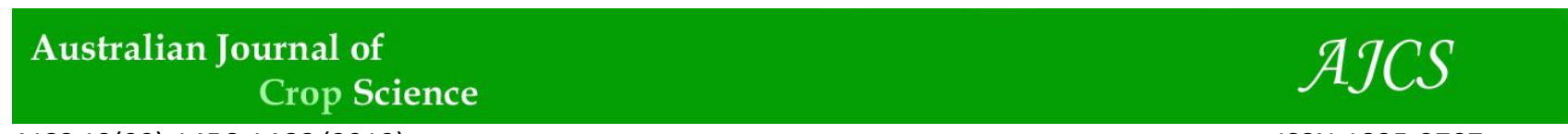

AJCS 13(09):1456-1466 (2019)

ISSN:1835-2707

doi: 10.21475/ajcs.19.13.09.p1541

\title{
Phenological-metric algorithm for mapping soybean in savanna biome in Brazil
}

\author{
Bernard S. de Oliveira*1, Manuel E. Ferreira², Alexandre C. Coutinho³ , Júlio C. D. M. Esquerdo³ \\ 'Mauro Borges Statistic and Socioeconomic Institute (IMB), Goiás, Brazil \\ ${ }^{2}$ Socio-Environmental Studies Institute/Image Processing and Geoprocessing Laboratory (IESA/LAPIG), Federal \\ University of Goiás (UFG), Goiânia, Goiás, Brazil \\ ${ }^{3}$ Embrapa Agricultural Informatics, Brazilian Agricultural Research Corporation (Embrapa), Campinas, São Paulo, \\ Brazil
}

*Corresponding author: so_geoprocessamento@yahoo.com.br

\begin{abstract}
Agricultural expansion in Brazil is still intense for commodities (such soybeans and corn), mostly cultivated over large portions of the Cerrado biome. Therefore, the development and application of techniques based on remote sensing to map crop areas at a regional level, in a dynamic and more precise way is urgently necessary. In this context, the objective of this study is the improvement of techniques for mapping soybean crops in Brazil, through an analysis of the Centro Goiano mesoregion of Goiás state (a core area of Cerrado), using a time series of Enhanced Vegetation Index (EVI) images provided by TERRA/MODIS orbital sensor, in a test period between 2002 and 2010. Despite their proven quality, MODIS EVI images already contain atmospheric interferences inherent to the acquisition process, such as the presence of clouds. Thus, a set of methods to minimize such artifacts was applied to the data of this study. In general, the methodological procedures comprise of (1) the application of the pixel reliability band aiming to remove pixels contaminated by clouds; (2) the use of contaminated pixel estimates (excluded from the time series); (3) application of an interpolation filter to fill the void pixels in each scene, obtaining continuous and smoothed spectral-temporal profiles for each land use classes; and (4) the classification of agricultural areas using a specific algorithm for crops in the Cerrado region of Goiás. The areas reconstituted in the images matched neighboring pixels, maintaining good coherence with the original data. Likewise, areas mapped with soybeans had a high correlation with official IBGE census data, with a global accuracy value of $78 \%$, and Pearson Correlation coefficient of 0.64 . The application of this technique to other imagery sensors (such as RapidEye, Landsat 8 and Sentinel 2) is highly encouraged due a better spatial and temporal resolution (when applied together in a temporal image cube), ensuring more efficient crop monitoring in Brazil.
\end{abstract}

Keywords: Agriculture, Cerrado biome, Temporal-mapping algorithm.

Abbreviations: MODIS_Moderate Resolution Imaging Spectroradiometer, EVI_Enhanced Vegetation Index), IDL_Interactive Data Languague Programming Languange, MOD13Q1_Product from MODIS, corresponding to 16 days compositing image mosaic and respective EVI vegetation index mosaic, TERRA_orbital platform with MODIS sensor, $R^{2}$ _determination coefficient, IBGE_Brazilian Institute of Geography and Statistics.

\section{Introduction}

In the early 2010, Brazil has stood out as one of the largest exporters of agricultural products in the world. Ethanol ranked first (a result of high interest in biofuels), followed by soybeans and corn (traditional commodities in the country). Currently, the main destinations for the export of Brazilian agricultural products are the European Union (US\$ 20.4 billion), China (US\$ 11 billion), the United States (US\$ 5.4 billion), Russia (US\$ 4.6 billion), Japan (US\$ 2.4 billion), and other countries (US\$ 33 billion) (MAPA, 2010). In 2017, for instance, Brazil exported soybean to many countries, especially to China (US\$ 20 billion), Spain (US\$ 758 million), Thailand (US\$ 623 million), the Netherlands (US\$ 592 million) and Iran (US\$ 469 million) (MAPA, 2018).

As already expected, Brazilian export levels have led to fast growth in agricultural production. An example of this dynamic is grain production, which rose from 17.4 million tons in 1960 to 207 million tons in 2015 , increasing over $800 \%$ in the last 50 years (MAPA, 2018). In addition to the aforementioned growth in grain production, there was also an increase in cultivated areas, from 22 million hectares in 1960 to 58 million hectares in 2018 (MAPA, 2018).

This new agricultural frontier affected Brazil in several ways. It is always associated with phenomena such as migration and economic occupation of the "new" territory (Borges, 1996; Ferreira et al. 2013), provoking the need to locate, delimit and understand such expansion, as well as the significant role of agriculture in the face of different national realities and contexts. According to Vale (2017), the expansion of the agricultural frontier occurred more noticeably in the CentralWest and North regions of Brazil due to the demand of agricultural products destined for the foreign markets, such as soybean, sugar, and meat. 
The Brazilian Institute of Geography and Statistics (IBGE) conducts a monthly survey to monitor crops, reporting estimates of production, average yield, planted and harvested areas throughout the territory. Data from the systematic survey of agricultural production:

(SIDRA, https://sidra.ibge.gov.br/home/ipca15/brasil) are consolidated at a municipal level based on sample collections and on some degree of subjectivity.

On the other hand, given the great importance of locating the occurrences of agricultural practices, the Geosafras project, conducted by the National Supply Company (Conab), started in 2004 with the objective of improving and developing methodologies for mapping different crops in Brazil. This project provides data on crop area and productivity estimates, among others. However, all such large projects require significant resources, making them dependent on government initiatives that are not always in line with the needs for monitoring, databases and technologies.

In this context, remote sensing science for agricultural monitoring of large areas, such as vegetation indices images, has been applied. Spera et al. (2014), using MODIS imagery (MOD13Q1 Product), mapped the agricultural areas and identified their cycles (single or double cropping) for the state of Mato Grosso, from 2001 (August) to 2011 (July), using a decision tree pixel-by-pixel classifier. According to the results, between 2001 and 2011, the total area of crop lands in Mato Grosso was increased by $75 \%$, from 3.3 million to 5.8 million hectares. The amount of double croplands was increased sixfold, from 0.5 million hectares in 2001 to 2.9 million hectares in 2011, with rotation of soybean and corn cultivation. Another study, conducted by Ide et al. (2018), using temporal EVI images from MODIS sensor (2006 to 2015), identified irrigated areas in the Northeast region of Brazil, achieving good results through advanced classification techniques (Kappa index of 0.6, equivalent to good on a scale of 0 to 1 ).

Therefore, this study aims to develop, test and present a methodology for the generation of systematic geographic information about agricultural areas with low cost and high dynamism. To perform this study, we chose a test area in the Cerrado biome involving the Centro Goiano mesoregion in the center of Goiás state, highly representative of Brazilian agribusiness, especially soybean crops.

To this end, advanced remote sensing techniques with high temporal resolution were studied, developed and applied, pointing out new forms of mapping and monitoring agricultural crops for the aforementioned study area.

\section{Results}

The results of the application of pixel reliability band and temporal linear interpolation are shown in Figure 1 , which contains an example of a filtered image of clouds (Figure 1a), followed by the image reconstituted by temporal linear interpolation (Figure 1b). Figure 2 shows the temporal profile of $\mathrm{EVI}$ filtered by the pixel reliability band and temporally interpolated.

The use of pixel reliability band with digital values 0 and 1 caused the loss of information in the original EVI image, as shown in Figure 2a, since the composition of December 19 was marked by the rainy season in the state of Goiás. Figure $2 \mathrm{~b}$ shows a suitable reconstitution of absent pixels. In addition, there is homogeneity of pixels estimated by interpolation with pixels kept after EVI image filtering. Such care ensures that the reconstitution of the time series maintains the natural appearance of the targets.

The result of temporal linear interpolation can also be seen in Figure 2 through the spectral-temporal profile. Days 273, 289, $305,353,17,49$ and 81 (Julian calendar) have null values, since pixels suffered atmospheric interferences due to the presence of clouds. This problem is solved by using temporal linear interpolation, obtaining a "pre-smoothed" curve to be used in the study of phenology, and extraction of phenological metrics.

Figure 3 shows the smoothed profile by the model modified by Wardlow et al. (2006) for an EVI pixel that underwent temporal linear interpolation, where the original value of the pixel reliability band (with valid values, without clouds) can also be observed. In this Figure 3, the EVI temporal profile is smoothed according to value 1 of the pixel reliability band, considered as a marginal (regular) value. However, we observed that the values considered as absolute confidence (0) caused noises on days 1, 113 and 145. Between days 33 and 97, the values remained, with the originality of information prevailing, once the original model proposed by Wardlow et al. (2006), upon arriving on day 65 , would be replaced by the lowest value between the days 49 and 81 .

\section{spectral-temporal signatures}

After noise removal from EVI-MODIS images, spectraltemporal signatures of land use classes were generated, such as Cerrado (typical - Cerrado woodland, and shrubby Cerrado), Pastures, Forests and Agricultural areas, as shown by Figure 4 .

It is important to understand the spectral-temporal signatures of these classes, because temporal analyses have the same principle as spectral signatures (between satellite bands on the same date). They are used to verify which regions differentiate agriculture better from other classes of land use, over time.

The analysis of spectral-temporal responses showed that all classes have maximum EVI values between December and January (rainy periods), when targets present a greater photosynthetic capacity. Still based on Figure 4, we noted that the targets classified as Forests obtained a mean standard deviation of 0.05 , as there is not much natural variation in this class over time, thus becoming the "standard". Its high EVI values $(0.4-0.6)$ are due to the density of vegetation cover area and its high photosynthetic activity.

The classes Cerrado (Typical and shrubby-land) and Pastures have a similar spectral-temporal response tendency, but with different mean standard deviations, of 0.05 and 0.10 , respectively. This is due to greater interference of soil response with pastures during the dry season (May to September), with a lower vegetation coverage than Cerrado, and consequently with lower EVI values, ranging between 0.2 and 0.25 , while the Cerrado remained with an EVI value above 0.3 .

By analyzing the class Agricultural area, we found that its spectrum-temporal response is quite different from the other classes. The first spectral-temporal observation had maximum EVI value, close to 0.8 for soybean crops, while for other classes the variation was $0.5-0.6$. 
Table 1. Analysis of errors in soybean mapping, using the method of this study, in comparison to IBGE official data.

\begin{tabular}{ll}
\hline Mean error & 17758.40 \\
Mean square error & 53275.20 \\
Willmot Coef. Concordance & 0.33 \\
Coefficient of Determination & 0.41 \\
Correlation Coefficient & $\mathbf{0 . 6 4}$ \\
\hline
\end{tabular}

Table 2. Correlation determination degree and correlation level of soybean mapping and IBGE official data.

\begin{tabular}{ll}
\hline $\begin{array}{l}\text { Index Interval } \\
\text { (Correlation Determination) }\end{array}$ & Correlation Level \\
\hline 0 & No correlation \\
$0-0.3$ & Weak correlation \\
$0.3-0.6$ & Average correlation \\
$0.6-0.9$ & Strong correlation \\
$0.9-0.99$ & Very strong correlation \\
1 & Perfect correlation \\
\hline
\end{tabular}

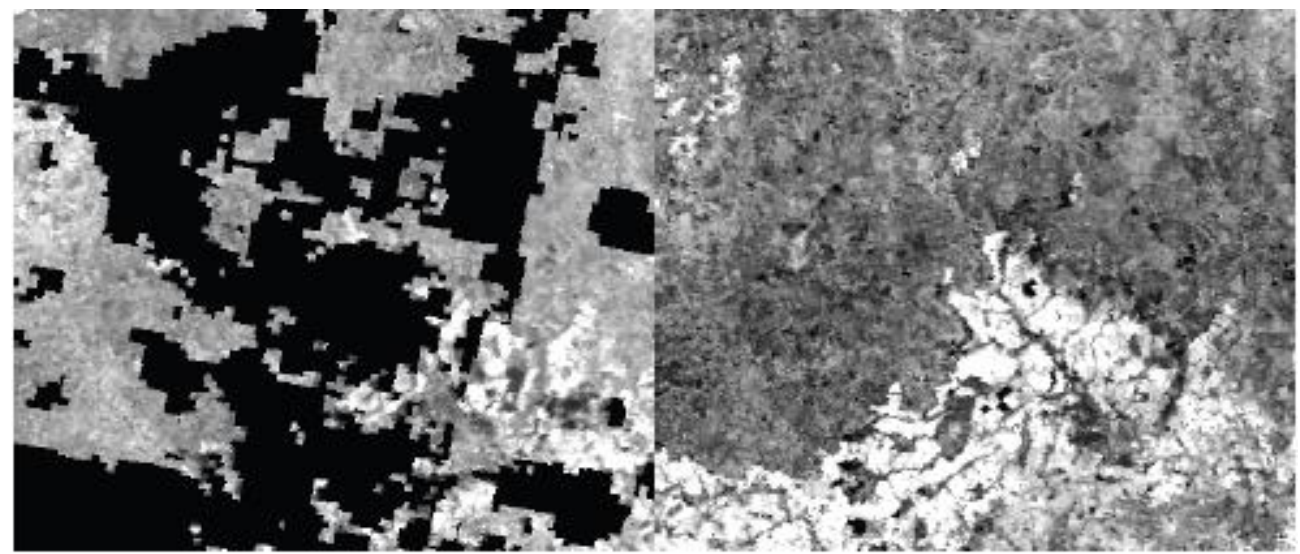

Fig 1. Example of an EVI image considering the application of the pixel reliability band (a) and an temporal interpolated EVI image (b) in the studied area. The bright pixels refer to soybean croplands.

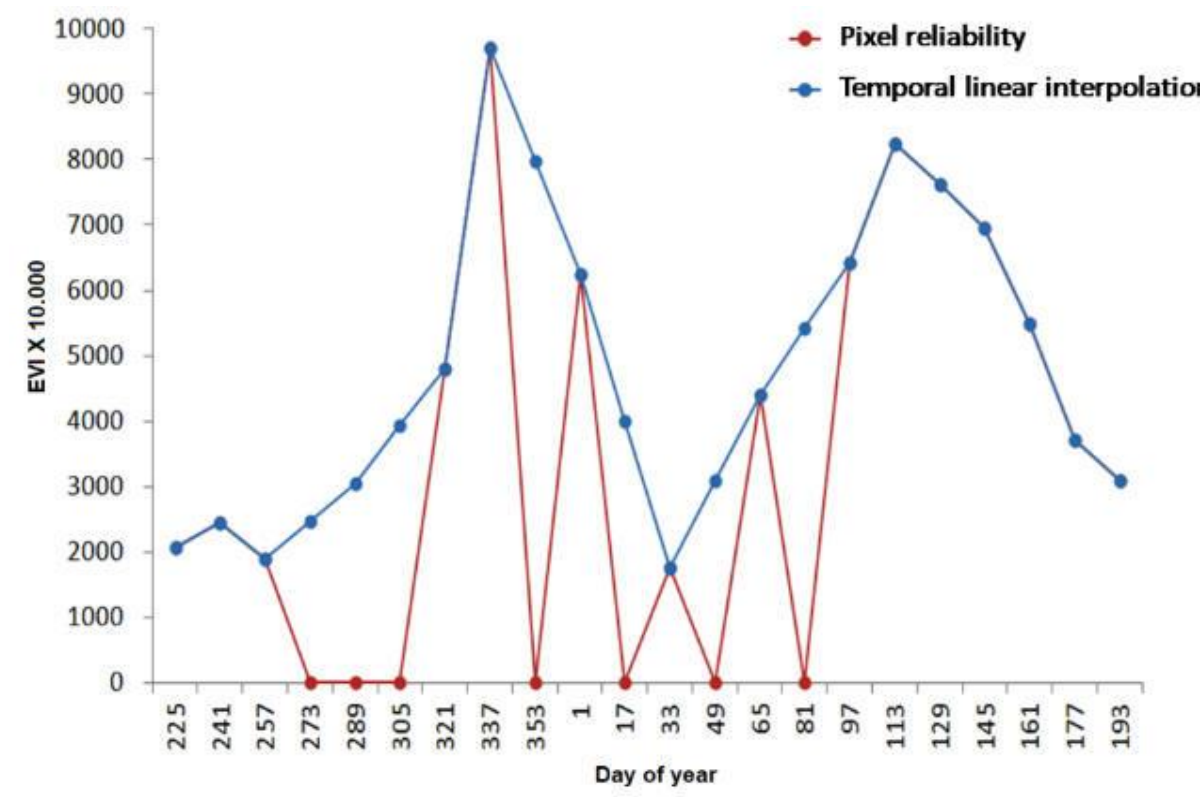

Fig 2. Temporal time profile on a reconstituted EVI image cube (in a specific area with soybeans), generated with the pixel reliability band and temporal linear interpolation. 


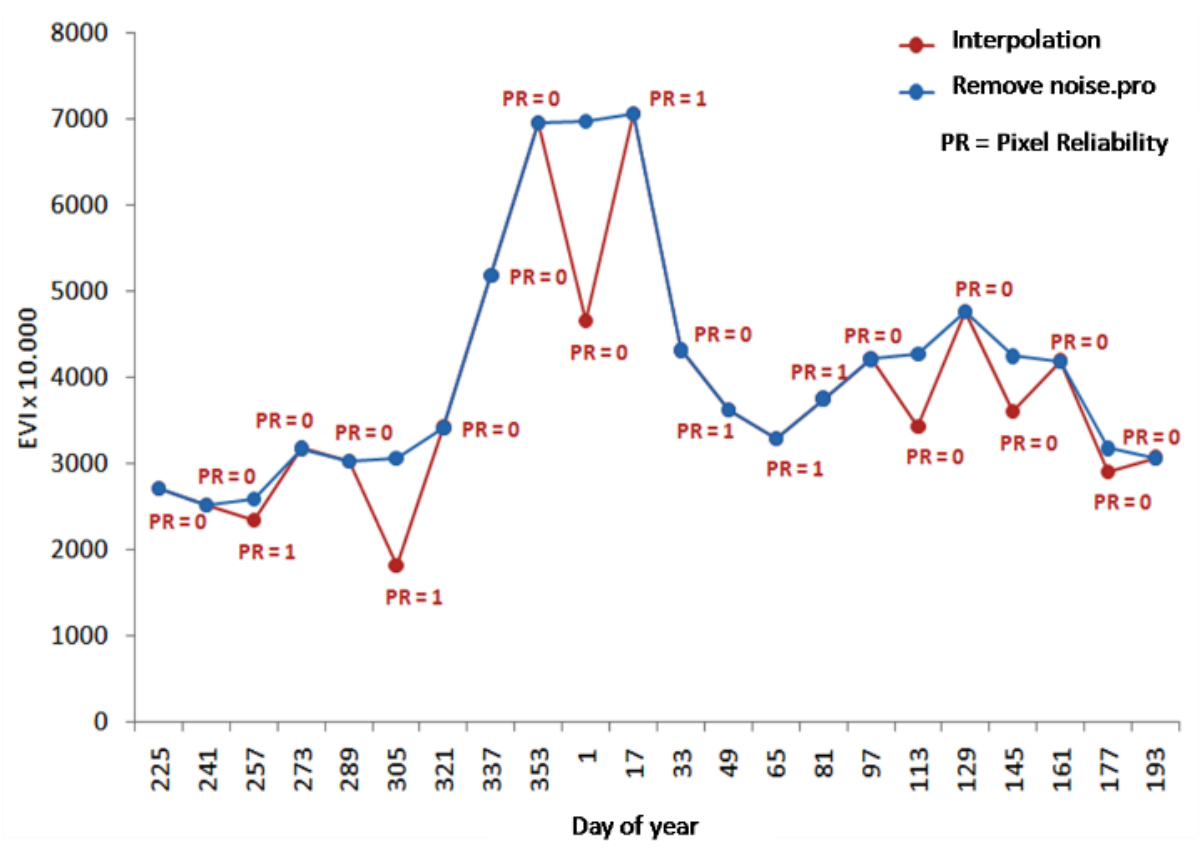

Fig 3. Profile of the algorithm RemoveNoise.pro.

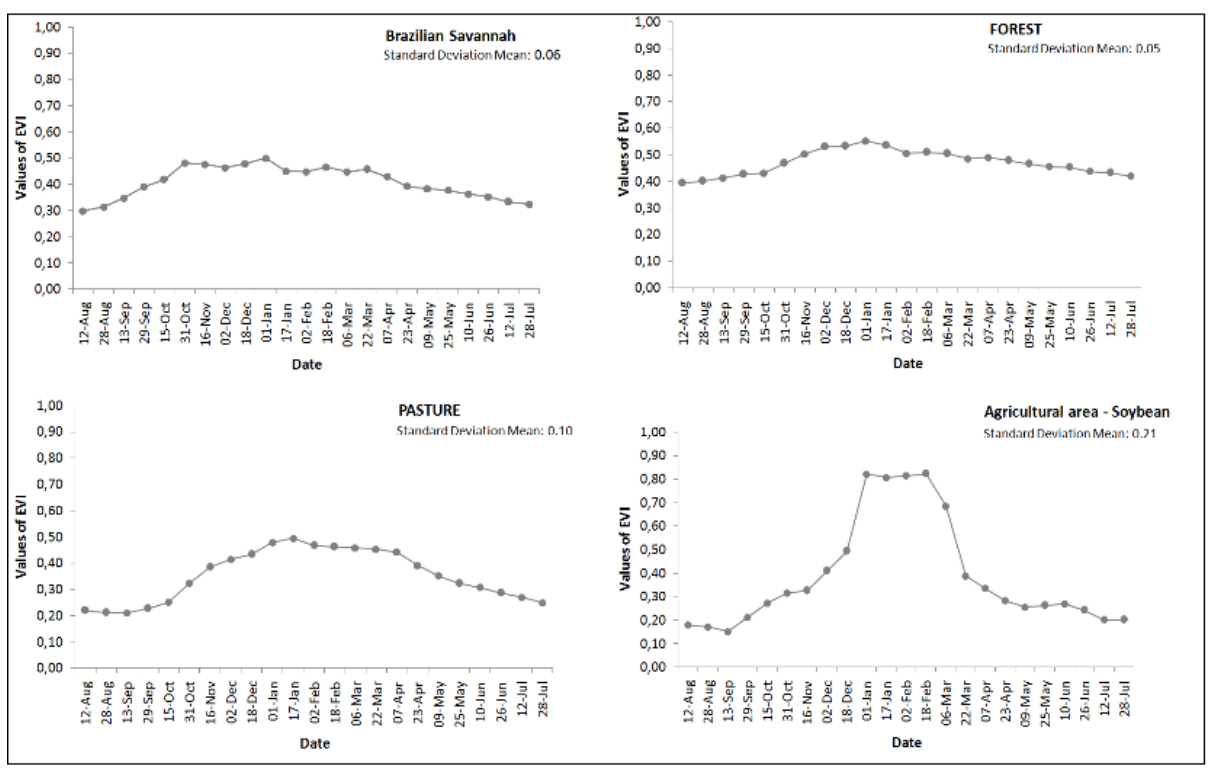

Fig 4. Spectral-temporal signatures of land use classes: (a) Cerrado, (b) Forests, (c) Pastures and (d) Agricultural area (soybean).

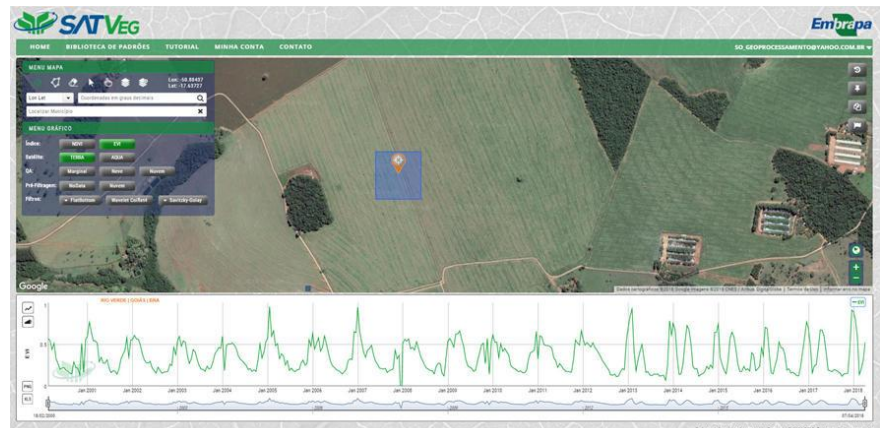

Fig 5. Example of an online analysis conducted at the Temporal Vegetation Analysis System (SATVeg) platform. Source: Embrapa (2018) (www.satveg.cnptia.embrapa.br). 


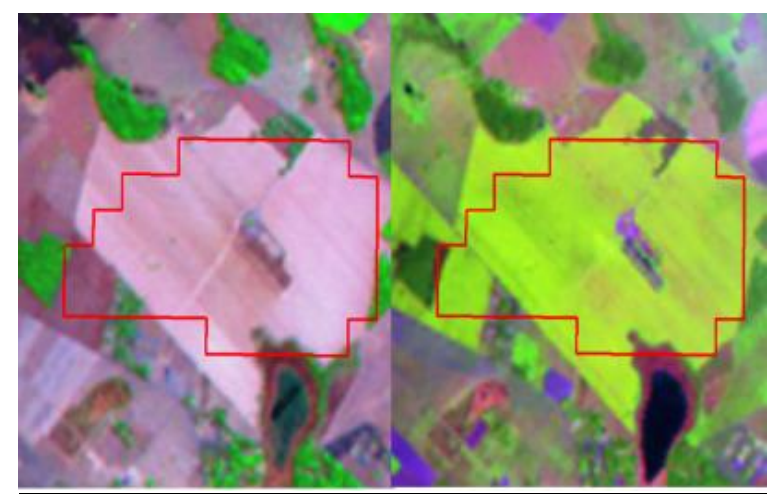

Fig 6. Example of agricultural field area within the study area (polygon with red border), identified automatically with our algorithm in the 2009/2010 harvest, over a Landsat 5 - TM sensor image (a) of August 2009 scene (left), and (b) January 2010 scene (right).

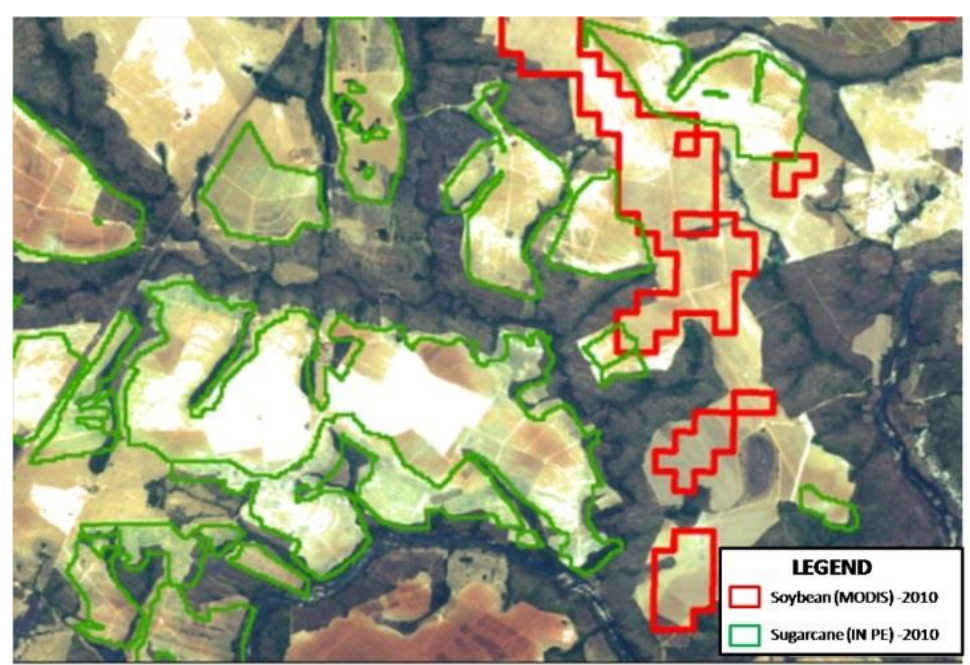

Fig 7. Examples of soybean polygons (red lines) in the 2010/2011 harvest, classified automatically with our algorithm, near to sugarcane polygons (green lines, CANASAT data) also in the 2010/2011 harvest.

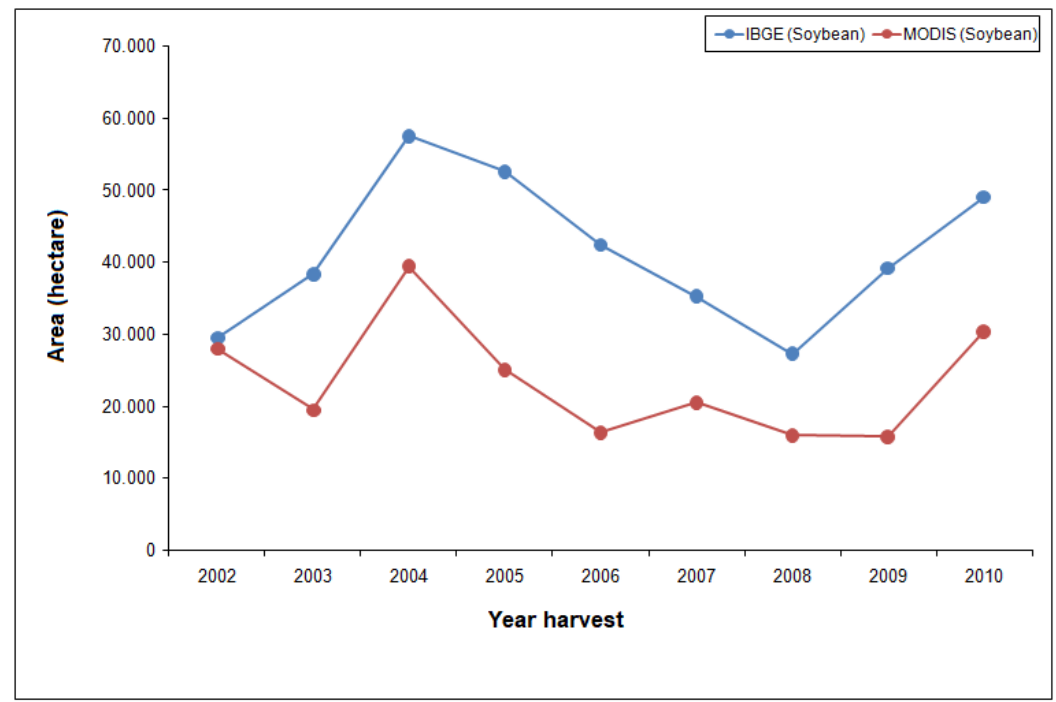

Fig 8. Comparison of soybean planted areas, classified automatically with our algorithm, versus IBGE official data, considering the Centro Goiano mesoregion. 


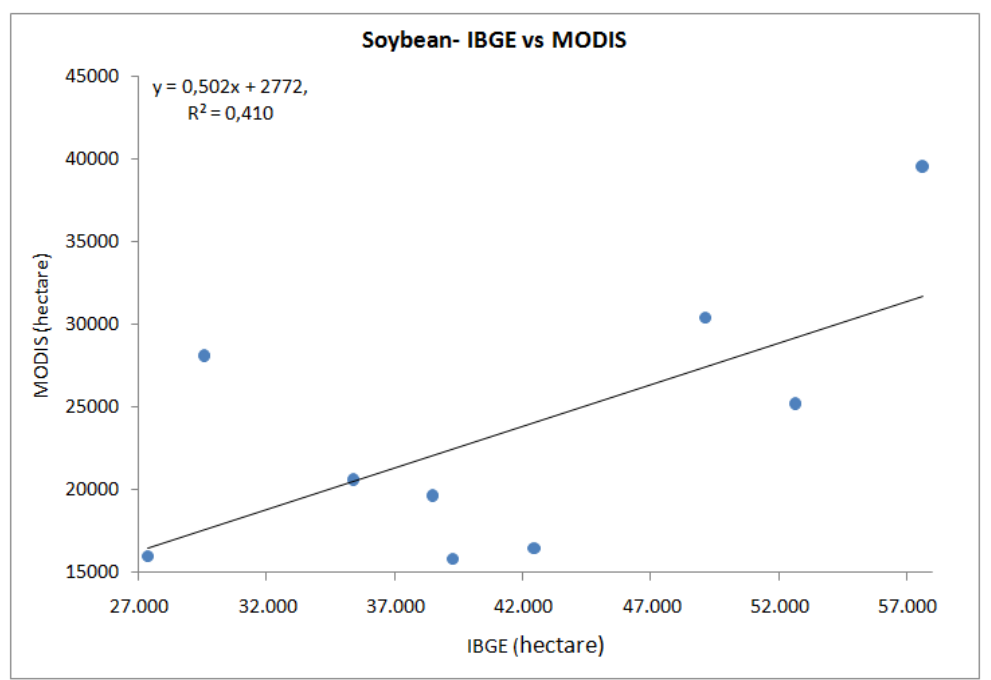

Fig 9. Coefficient of determination for the soybean croplands, classified automatically with our algorithm, versus IBGE official data (2006), considering the Centro Goiano mesoregion.

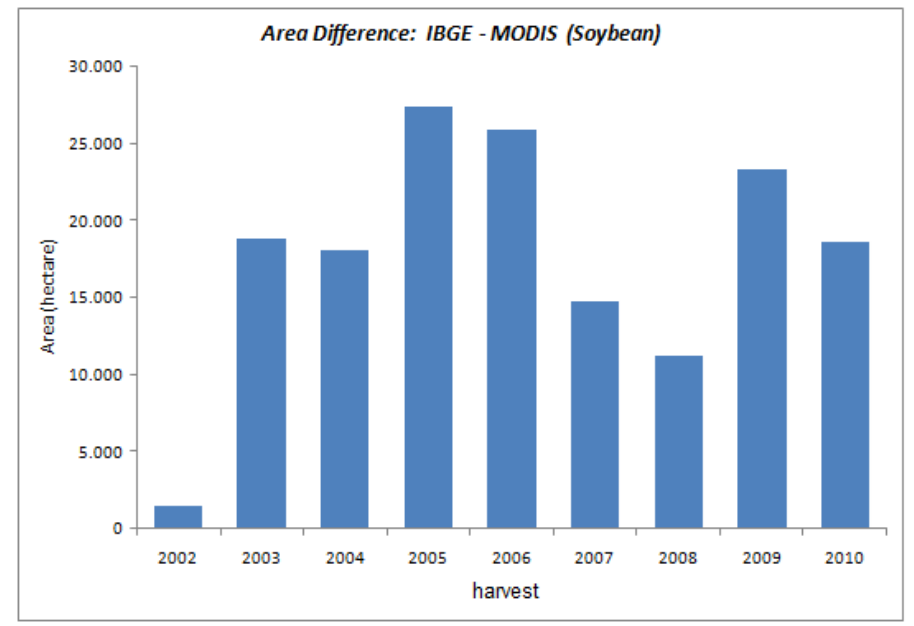

Fig 10. Difference of soybean croplands area, classified automatically with our algorithm, versus IBGE official data, considering the Centro Goiano mesoregion.

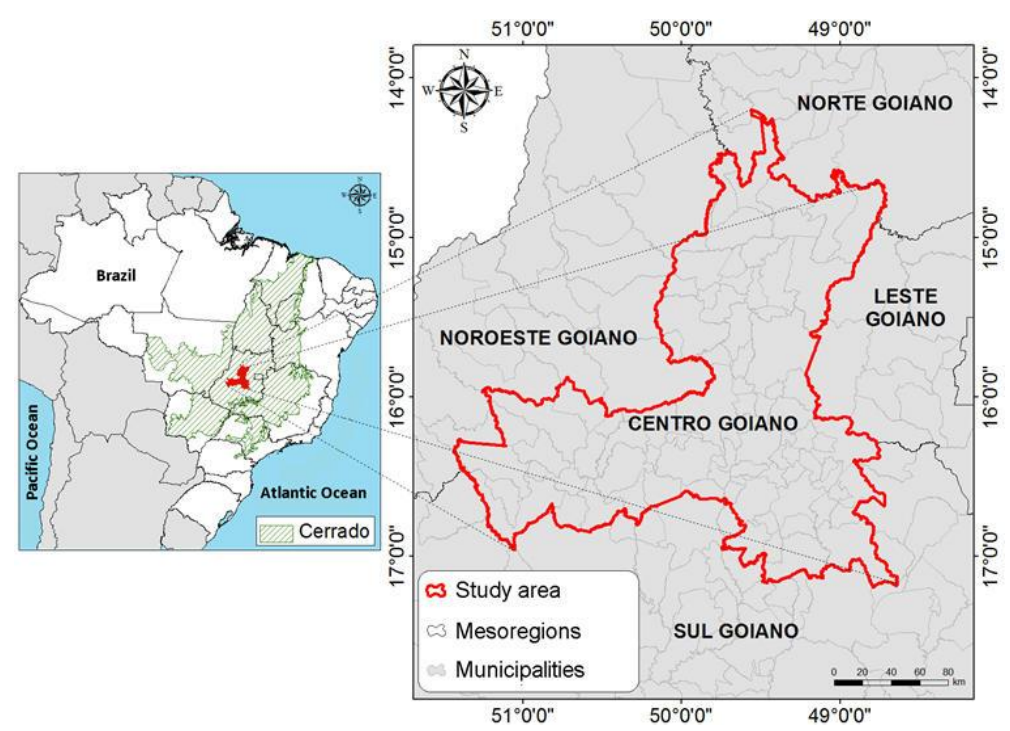

Fig 11. Study area with emphasis on the Centro Goiano mesoregion, state of Goiás. 


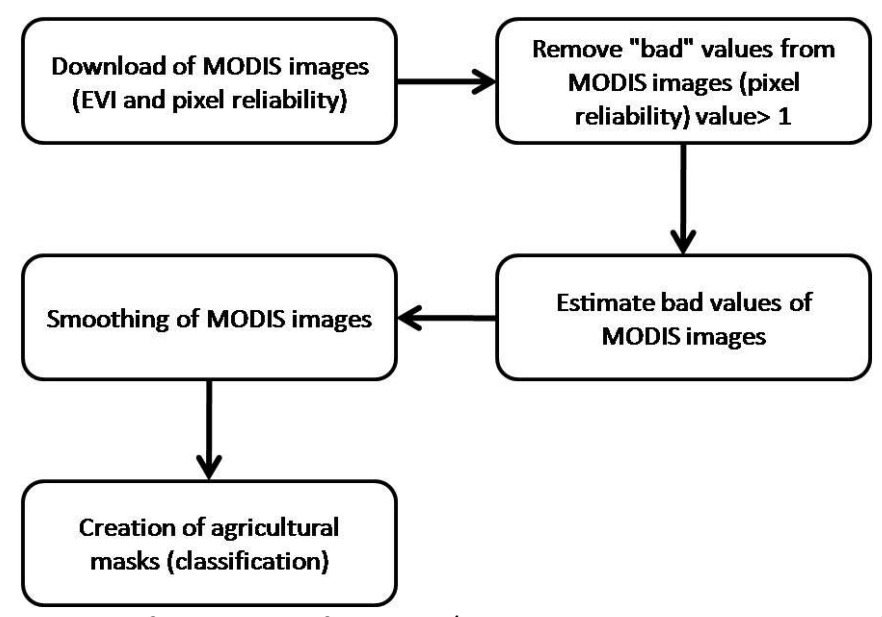

Fig 12. Processing flow diagram for TERRA/MODIS images in crop area classification.
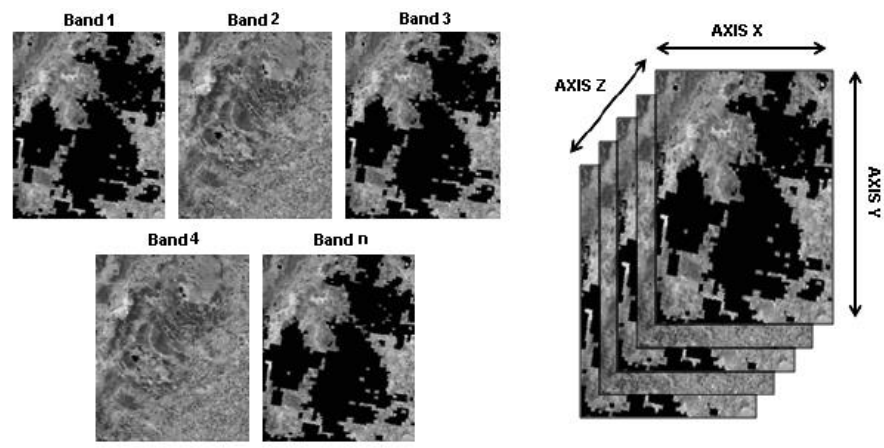

Fig 13. Stacking of filtered EVI images (black spaces represent areas with clouds); each layer/band represents a date in the classification of agricultural areas.

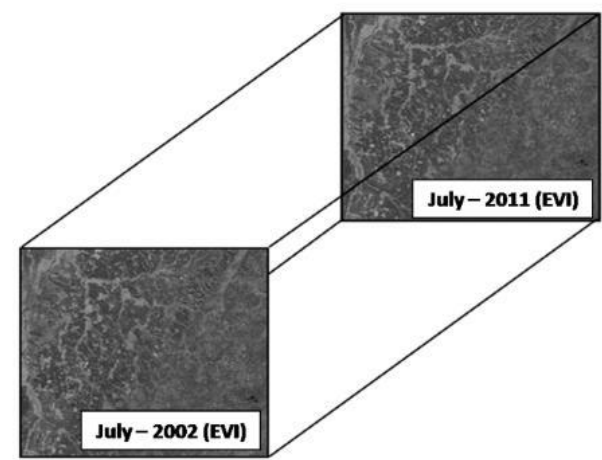

Fig 14. Example of stacking of filtered images based on dates of scenes available in the database, used in the classification of agricultural areas.
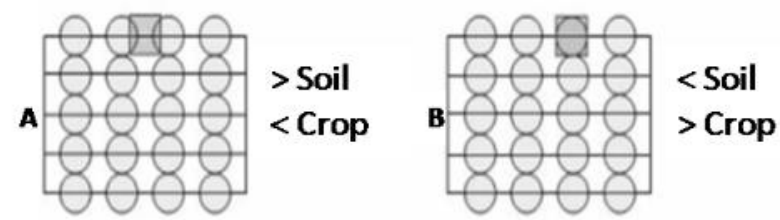

Canopy projection of crop

Pixel position(i) by scan line(n)

Fig 15. Projection of the field sensor over the surface (IFOV - Instantaneous Field of View). 


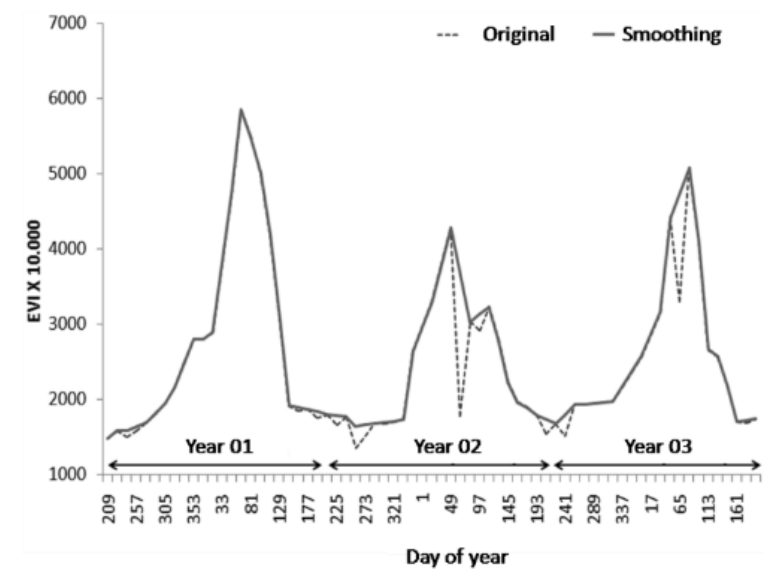

Fig 16. Pre-processed/original (dashed line) and post-processed profiles using the RemoveNoise.pro algorithm.

This phenomenon, represented by these land use classes, is also illustrated by the Temporal Vegetation Analysis System (SATVeg; Embrapa, 2018; Figure 5) in an online platform, by which the same spectral-temporal behaviors are observed. Regarding the observation of low EVI values from August to the end of September, and from May to July (months from the pre-planting to post-harvest of crops, respectively), we noted that the EVI value was below 0.2 , while in the other classes, it was higher than this. From October, there is an increase in EVI values in agricultural areas, which represents the germination period (initial growth), until January, the peak of phenological development. In the second half of January, the values decrease (senescence), motivating the harvest of the crop.

Figure 6 shows the vector limit of the area planted with soybeans (over a Landsat image) in the municipality of Bela Vista de Goiás, automatically generated by the algorithm developed in this study. The algorithm is based on TERRA/MODIS EVI data in the 2009/2010 harvest, using statistical methods and phenological vegetation metrics.

The Landsat 5 - TM sensor image, obtained in January 2010 (Figure 6b), shows that the soybean area was well identified by the method developed in this study. When soybean areas are not delimited by the method, it is due to a spectral mixture in the pixel and a spatial resolution of MODIS (250 meters using the MOD13Q1 product). These changes are response of pixels over time, resulting in standard deviation and a phenological metric that are different from those attributed to pure soybean pixels.

Figure 7 indicates areas mapped with soybeans (red lines), based on the method proposed in this study, close to areas mapped with sugarcane (green lines)-CANASAT project (INPE; http://www.dsr.inpe.br/laf/canasat/en/), both in the 2010/2011 harvest.

We verified that the CANASAT sugarcane mapped by visual inspection (with Landsat - 5 and 8 dataset) did not overlap soybean crop areas mapped automatically by the method proposed in this study. Taking into account the different spatial resolutions (MODIS has a pixel approximately 64 times larger than the Landsat), it can be considered as a map with a good precision.

Figures 8,9 and 10 show a comparative analysis between soybean plantation areas indicated by the IBGE with data obtained in this study (provided by the MODIS/EVI scenes). By correlation analyses $\left(R^{2}\right)$ for areas planted with soybeans in Centro Goiano, Tables 1 and 2 present some statistical parameters derived from the comparison of this analysis with official data of the Federal Government (IBGE) (concordance, mean square error, correlation and determination coefficients).

Specifically, in the graph of Figure $\underline{8}$, which shows a variation in soybean plantations in the Centro Goiano mesoregion, there is a certain match between data mapped in this study and IBGE census data. However, there is still a marked oscillation in our data, which may be attributed to a lower spatial resolution of the MODIS sensor/smaller mapping scale, noise/clouds (largely solved using algorithms to estimate natural values without noise), and delays in rainfall/abnormal variation of EVI. On the other hand, IBGE data are collected from samples in loco, based on farmers' estimates, once a year, which may also widen the differences between the two methods. In this sense, in addition to the automatic nature of this study's method, it should be noted that the data obtained are geographically explicit (and not from census), which enables a series of socio-environmental analyses and indicators.

According to the data in Tables 1 and 2, soybean areas mapped by MODIS had a correlation value (Pearson Correlation Coefficient) of 0.64 , followed by a coefficient of determination $\left(r^{2}\right)$ of 0.41 , and a coefficient of concordance (Willmott) of 0.33 .

\section{Discussion}

The model adopted in this study caused only abrupt noises (large difference in values between the observed value and its neighborhood) to be corrected, avoiding distortions (with much information estimated) and omissions of important phenological characteristics in the agricultural mapping, such as the growth period of plant vigor (germination).

Noise also causes variations in the standard deviation in pixels over time, due to the variability of a set of values around the mean. Thus, in addition to improving the identification of phenological metrics, smoothing improves performance and shows, with more harmony, the responsespectrum-temporal variability of the target without inclusion errors (commission).

Based on such mappings and numbers, it can be seen that soybean crops maintained a tendency with the area estimated by the IBGE, with a mean difference of 17,758 ha in 
the study period (Figure 8), considering all the municipalities of the Centro Goiano mesoregion. As a comparison, in the study conducted by Silva et al. (2009), using a similar database for the year 2009, an average difference of 11,375 ha was found in relation to IBGE census data in Silvânia, Luziânia, Cristalina municipalities, with large farms of soybean production. It is worth mentioning that the Centro Goiano mesoregion has, in general, small filed farms, which contributes to the significant difference shown by Figures 9 and 10.

This means that the mapping had a good correlation and a reasonable determination with IBGE census data, since its correspondence (Person Correlation) was 64\%, with the determination of the model $\left(r^{2}\right)$ of $41 \%$ with actual land data (in this case, IBGE). We know, therefore, that the larger the area analyzed, the higher this correlation with IBGE will be, because the differences would tend to decrease with the reduction of the mapping scale.

Regarding accuracy analyses of mapping through Global Accuracy, this soybean mapping (Centro Goiano mesoregion) had an accuracy value of $78 \%$ based on 50 random sample points in the study area. Other studies also reached similar results, such as that of Ambika et al. (2016), which used MODIS images to map an irrigated area mapping in India, from 2000 to 2015 , finding a $95 \%$ correlation $\left(R^{2}=0.95\right)$, in order to understand the inter-annual variability in the irrigated area on various spatial scales. Zhu et al. (2016), using images from MODIS and LANDSAT (TM), extracted the crop phenology from filtered EVI images (with noise removal), seasonal dynamic index (SDI), and crop fraction based on the SDI relationship with LANDSAT. The authors obtained a RMSE of 0.14 from random samples. Cechim Junior et al. (2017) used minimum and maximum EVI images representing the planting and harvesting periods of the Alto Paraguay basin for the mapping of summer crops between $2000 / 2001$ and 2015/2016, with kappa values of 0.85 and 0.86 , respectively

\section{Materials and Methods}

\section{Study area}

The study area is the Centro Goiano mesoregion, located at the center of the state of Goiás (a core area of the savanna biome in Brazil, locally known as Cerrado), composed of 82 municipalities and 6 microregions, covering an area of 40,836 $\mathrm{km}^{2}$ between $17^{\circ} 13^{\prime}$ and $14^{\circ} 12^{\prime} \mathrm{S}$ and $48^{\circ} 25^{\prime}$ and $48^{\circ} 36^{\prime} \mathrm{W}$, as shown in Figure 11.

This area has seven classes of soils: Argisols, Cambisols, Chernosols, Gleysols, Latosols, Neosols and Plinthosols, with a predominance of Latosols, equivalent to $41.57 \%$ of the total area. According to Palmieri and Larach (2006), Latosol is a non-hydromorphic soil, with little perceptible chemical, physical and mineralogical properties of along its profile. Its particle size varies from medium to very clayey, and it is widely used for agricultural purposes.

\section{Database}

In this study we used Enhanced Vegetation Index images (EVI) (MODIS orbital sensor, MOD13Q1 Product), with bands of $250 \mathrm{~m}$ of spatial resolution, acquired free of charge from a
NASA gateway (<http://reverb.echo.nasa.gov/>, currently migrating requests to the:

portal<https://earthdata.nasa.gov>). All MODIS images were originally obtained in the HDF format using Sinusoidal projection. The MODIS Reprojection Tools (MRT) software, also free, was used to convert them to Geotiff format and Geographic projection (Datum WGS 84).

A resolution of $250 \mathrm{~m}$ is suitable for the mapping of large agricultural fileds. Data contain daily revisions, favoring the consolidation of maximum compositions every 16 days (maintaining the highest EVI value, cloud filtration, over 64 observations/month for the same area), sufficient for phenological analyses of vegetation. According to Marh (2011), the images of the MODIS sensor, aboard the TERRA orbital platform, show less cloud interference depending on the time of the passage of this satellite over the Equator (10:30 a.m.). Images provided by the same sensor, but aboard the AQUA platform, show more clouds around that region due to its time of passage (1:30 p.m.). For this reason, we chose the images of the TERRA/MODIS.

\section{Processing of TERRA/MODIS images}

Figure 12 shows the steps in the treatment of TERRA/MODIS images. Pixel reliability is an image type available in the product MOD13Q1 obtained from the MODIS collection 5, which presents the use reliability of each pixel considering data on the sensor imaging angle, atmospheric interferences (clouds and other aerosols), snow and shadows (NASA, 2012). Initially, an algorithm was created in the Interactive Data Language (IDL) software to eliminate cloud-contaminated pixels from EVI images according to the pixel value of the pixel reliability band.

Originally, the pixels of EVI images corresponding to 0 and 1 in the pixel reliability band kept the original values, while values corresponding to 2 and 3 (less reliable for mappings) were assigned with the value 0 .

Pixels with values 0 and 1 indicated by the pixel reliability band represent low atmospheric interference during the entire period of maximum EVI (December/January, rainy months, corresponding to the peak of soybean cultivation in Brazil).

A second algorithm in IDL was developed with the objective of stacking all filtered EVI images automatically, organizing them according to year and month, as seen in the Figure $\underline{13}$.

The selection of images must highlight agricultural areas. For that, we used dates that defined the beginning and the end of the agricultural calendar in Goiás.

Thus, the stacking of images began on August 12 (valid for any year analyzed), the date before the soybean planting period (for example), and ended on July 27 , the period that marks the end of the cycle or the agricultural year, according to Figure 14.

After the stacking of filtered EVI images (areas were discarded when clouds were present), a third algorithm was used to estimate the values of pixels discarded during filtering and for invalid data (between 0 and $-3,000$ ). This algorithm works by temporal linear interpolation using values of "good" pixels in images before and after the discarded pixel.

The temporal linear interpolation is performed using an arithmetic mean between the previous and the posterior image. If the previous image has a pixel value of 0 , the 
algorithm jumps to the next image until it finds a valid pixel value for the EVI other than 0 (zero).

When the algorithm finds a value other than 0 , it sums the value of the valid pixel of the previous image with the value of the valid pixel of the posterior image (different from 0 ), dividing this result by the total of images, according to equation 1 .

$E v=\frac{p v v+p o v v}{n}$

(Eq.1)

Where:

$E v=$ estimated value;

$p v v=$ previous valid value;

povv = posterior valid value;

$n=$ numbers of temporal pixels.

After the division, the algorithm assumes the value of the previous image and adds the result of this division to all pixels with a value of 0 .

During processing, we avoided interpolation with neighboring pixel values by inserting values other than agricultural crops, as neighboring pixels may contain other types of objects, as shown in Figure 15.

In order to eliminate noises in EVI images, as shown in Figure 13 , there was a need to smooth such images. In order to do so, the RemoveNoise.pro algorithm was created in the IDL environment to remove values considered noisy (inconsistent) (Wardlow et al., 2006). They were replaced by $10 \%$ of the lowest neighborhood value, so that the filtered series maintained a behavior close to natural, as shown in Figure $\underline{16}$.

\section{Classification step}

The mapping of agricultural areas began with the division of 207 stacked images into 9 "cubes of images" (equivalent to nine crops), 23 scenes per cube, representing the year analyzed (practically two bands or images per month already filtered, stacked and interpolated). After separating the images, we calculated the standard deviation of each pixel in each image cube.

The pixel with a standard deviation value above 0.2 was considered a soybean cultivated area; according to verification in the field (soybean plantations), the average of the standard deviation for this crop is generally above 0.2. If the pixel presents a standard deviation value between 0.14 and 0.2 , it is selected for other analyses, such as verification of EVI values in the initial and final harvest period, maximum $\mathrm{EVI}$ value in the time series and analysis of full flowering. The following is a better description of such mapping rules:

- Initial and final period of harvest: If the EVI value in the initial and final period is less than or equal to 0.3 , the pixel tends to be an agricultural area because, in areas occupied by forests, pastures and native Cerrado, the initial and final period has an $\mathrm{EVI}$ value above 0.3 .

- Maximum value of time spectrum signature: If the maximum value of $\mathrm{EVI}$ in the time series is above 0.5 , there is a possibility that the pixel is an agricultural area, since the average maximum value of pastures and native Cerrado is less than or equal to 0.5 .
After completing the selection steps, the algorithm searches for the maximum corrected EVI value, which is the average between the maximum EVI value and the highest EVI value of neighboring pixels. This procedure is performed to simulate the stages of full flowering and grain filling (in the case of soybeans). To classify soybean areas, we used the left amplitude, which is the subtraction of the corrected maximum value of EVI from the EVI value that marks the beginning of the photosynthetic activity of the crop (germination).

To find the value of EVI characterized as germination, we developed an algorithm that verifies the growth in EVI values considering three observations over time. In one of them, the $\mathrm{EVI}$ value has a growth of 4,000 (equivalent to 0.4 on a scale from 0 to 1 ).

After finding the EVI value characterized as germination, we subtracted from it the maximum EVI value over time. With this, the left amplitude is defined (in synthesis, one pixel is captured by vegetation growth). If the left amplitude value is above 0.55 , the pixel is classified as soy.

In order to map irrigated agriculture areas (pivots), EVI values were verified at the beginning and at the end of the harvest. If the EVI value is above 0.4 and the standard deviation is equal to or greater than 0.2 , the pixel is considered an irrigated agriculture area, since irrigated agriculture areas have a high variation of EVI values throughout the year, as well as high values of EVI during the dry period. This is common in the state of Goiás between May and September (dry season).

\section{Conclusion}

The method developed and tested in this study may be applied to any temporal series of satellite images, especially with MODIS dataset (250 meters of spatial resolution in compositing generated every 16 days, with few clouds). If the image has a medium-high spatial resolution, it will be possible to extract information from agricultural areas smaller than 6.25 hectares ( $\sim$ minimum area of MODIS pixel). According to statistical analysis, soybean areas mapped by MODIS had a good correlation with IBGE official data, with a similar trend of increase and decrease in agricultural production, favoring the application of the method (despite differences in area, the trend is obtained by region, river basin or municipality). Regarding the accuracy analyses of mapping through Global Accuracy, the mapping obtained with MODIS also presented good accuracy (78\%). Finally, the application of this technique to other orbital sensors (such as RapidEye, Landsat 8 and Sentinel 2) is highly encouraged. Other crops besides soybean may be incorporated into this algorithm, extending the mapping to other regions of interest in Brazil.

\section{Acknowledgements}

We thank Embrapa Agricultural Informatics, under the MAPAGRI Project (Methodology for Mapping the Brazilian Agriculture) for the scholarship granted to the first author. To FAPEG (Goiás state Research Foundation), within the scope of the Organization and Availability of Geographic Databases for Territorial and Environmental Management of the State of Goiás project (grant \#2012/10267000966). The second author was a CNPq Research Fellow (grant \#312229/2014-3). 


\section{References}

Ambika AK, Wardlow B, Mishra V (2016) Remotely sensed high resolution irrigated area mapping in India for 2000 to 2015. Sci. Data 3(160118): 1-14.

Borges BG (1996) A expansão da fronteira agrícola em Goiás. Hist. R. 1(2): 37-55. Available at: <https://www.revistas.ufg.br/historia/article/view/10932>. Accessed in: November 15, 2018.

Cechim Junior CL, Antunes JFG, Johann JA, Esquerdo JCDM (2017) Mapping of summer agricultural crops in the Alto Paraguai basin through EVI/MODIS time series. Geografia/Rio Claro 42(3): 129-143. Available at: <http://lcweb2.loc.gov/hlas/portugues/jabg.html>.

Accessed in: 15 November 2018.

Embrapa Informática Agropecuária (2017) SATVeg-Sistema de Análise Temporal da Vegetação. Available at: <https://www.satveg.cnptia.embrapa.br/satveg/login.html >. Accessed in: July 30, 2017.

Ferreira ME, Ferreira LG, Miziara F, Soares-Filho BS (2013) Modeling landscape dynamics in the central Brazilian savanna biome: future scenarios and perspectives for conservation. J Land Use Sci. 8(4): 403-421.

Ide AK, Baptista GMM (2018) Modis time series for irrigatedarea mapping in hydrographic basins of the Brazilian Northeastern region. Pesq. Agropec. Bras. 53(1): 80-89.

Mapa. Ministério da Agricultura Pecuária e Abastecimento (2010) Agronegócio Brasileiro Em Números. Available at: <http://www.agricultura.gov.br>. Accessed in: January 20, 2014.

- Ministério da Agricultura e Pecuária (2018) Agrostat Estatística do Comércio Exterior do Agronegócio Brasileiro. Available at: <http://sistemasweb.agricultura.gov.br/pages/AGROSTAT.h tml>. Accessed in: August 30, 2018.

- Ministério da Agricultura Pecuária e Abastecimento. Dados básicos de economia agrícola. Available at: <http://www.agricultura.gov.br/agroestatisticas/estatistica s-e-dados-basicos-de-economia-agricola>. Accessed in: September 17, 2018.
Marh DE (2011) Drivers of Land-Use Change in Mato Grosso: a ten-year MODIS analysis. 2011. 58p. Thesis (Degree Bachelor of Science in Environmental Science) - Brown University, Providence, Rhode Island. Available at: <http://www.dmahr.com/files/dmahr_thesis_final.pdf>. Accessed in: November 15, 2018

NASA. National Aeronautics and Space Administration (2012) MODIS Website. Available at: <http://modis.gsfc.nasa.gov/about/>. Accessed in: October 15, 2012.

Palmieri F, Larach JOI (2006) Pedologia e Geomorfologia. In: GUERRA AJT, CUNHA SBC da. (Org). Geomorfologia e Meio Ambiente. $6^{\text {th }} E d$, Bertrand Brasil, Rio de Janeiro, p. 59-119.

Silva RAB da, Souza ALF de, Campos PM, Bilich MR, Rocha JV (2009) Estimativa de área plantada de soja utilizando imagens MODIS, no Estado de Goiás. Paper presented at the brazilian remote sensing symposium, INPE, Natal, 483489 April 2009.

Spera SA, Cohn AS, Vanwey LK, Mustard JF, Rudorff BF, Risso J, Adami M (2014) Recent cropping frequency, expansion, and abandonment in Mato Grosso, Brazil had selective land characteristics. Environ. Res. Lett. 9(6): 1-12.

Vale NKAD (2017). Trajetória da produtividade da soja em função da variabilidade das chuvas no estado de Goiás. 2017. 63p. Dissertation (Master in Agribusiness) Universidade Federal de Goiás (UFG), Goiânia, Goiás. Available at: <https://repositorio.bc.ufg.br/tede/handle/tede/6997>. Accessed in: November 15, 2018.

Wardlow BD, Kastens JH, Egbert SL (2006) Using USDA Crop Progress data for the Evaluation of Greenup Onset date Calculated from MODIS 250-meter data. Photogramm. Eng. \& Rem. S. 72(11): 1225-1234.

Zhang X, Zhang M, Zheng Y, Wu B (2016) Crop mapping using PROBA- $V$ time series data at the Yucheng and Hongxing farm in China. Rem. S. 8(11): 1-18

Zhu C, Lu D, Victoria D, Dutra LV (2016) Mapping fractional cropland distribution in Mato Grosso, Brazil using time series MODIS enhanced vegetation index and Landsat Thematic Mapper data. Rem. S. 8(22): 1-14. 